\title{
Trabalho noturno e seus efeitos na saúde dos trabalhadores da área de segurança
}

\author{
Robinson Souza de França* \\ Raquel Pereira Belo** \\ Luisa Regina da Silva Teixeira*** \\ Pollyana Nathercia de Vasconcelos Rodrigues**** \\ Valéria Gomes de Arruda***** \\ Christian Gabriel Madeira Guimarães******
}

\begin{abstract}
Resumo
Este estudo empírico e qualitativo teve como objetivo conhecer os efeitos do trabalho noturno na saúde dos trabalhadores da área de segurança, para isto verificou os principais impactos do trabalho na sua saúde e realizou um levantamento dos seus motivos para a escolha da profissão. Vinte trabalhadores da área de Segurança pública e privada responderam entrevista semiestruturada acerca do trabalho noturno e os impactos na saúde dos profissionais e questionário sociodemográfico. Suas respostas foram processadas no software IRAMUTEQ, cuja classificação hierárquica descendente as dividiu em quatro classes, fatores motivadores e desmotivadores para o trabalho noturno, atividades fora do horário de trabalho e repercussões do trabalho na vida pessoal. Os resultados apontam que as queixas de cansaço físico e psíquico, estresse, desregulação do ciclo do sono e impactos nos relacionamentos sociais estão associados aos processos de adoecimento e sofrimento físicos e psíquicos no trabalho noturno.

Palavras-chave: Trabalho Noturno; Saúde; Trabalho na Segurança.
\end{abstract}

\section{Night work and its effects on the health of safety workers}

\begin{abstract}
This empirical and qualitative study aimed to Know the effects of night work on the health of workers in the safety area, for this it verified the main impacts of the work on their health and conducted a survey of their reasons for choosing the profession.

Twenty public and private security workers answered a semi-structured interviews about night work and the health impacts of professionals and sociodemographic questionnaire.Their answers were processed in the IRAMUTEQ software, whose descending hierarchical classification divided them into four classes, motivating and demotivating factors for night work,activities outside of Working hours and repercussions of work on personal life. The results indicate that complaints of physical and psychic tiredness, stress, sleep cycle dysregulation and impacts on social relationships are associated with the processes of physical and mental illness and suffering at night work.

Keywords: Night work; Health; Security Work.
\end{abstract}

* Psicólogo e mestrando em Psicologia pela UFPI

** Psicóloga, Mestre e Dra. pela UFPB. Profa. Associada 1 (UFPI)

***Graduada em Psicologia (UFPI)

****Psicóloga pela Universidade Federal do Piauí - (UFPI)

***** Psicóloga pela Universidade Federal do Piauí - (UFPI)

******Graduando em psicologia (UFPI) 


\section{Introdução}

O trabalho rege a vida, a organização do tempo, das relações interpessoais e dos grupos sociais. A humanidade se estrutura, histórica e politicamente, quase em sua totalidade, em função do conceito de trabalho, desde os caçadores da era paleolítica aos fazendeiros, artesãos medievais, operários da linha de montagem do século XX e profissionais da área técnico-científica informacional atual (Araújo \& Sachuk, 2007).

O trabalho humano por muito tempo não foi pensado como parte significativa da vida das pessoas, ainda que aspectos como a saúde do trabalhador seja influenciada pelo trabalho que ele desempenha. O trabalho começa a fazer parte da vida das pessoas e se torna significativo a ponto de ser equivalente às relações amorosas que elas constroem e tão necessário quanto o sono, podendo satisfazer as suas necessidades básicas. Entretanto, no campo da saúde mental, o trabalho foi tardiamente integrado como fator de atenção nos estudos, vindo, então, a ser pesquisado efetivamente em décadas recentes (Borsoi, 2007).

A concepção de que o trabalho não influencia o ser humano dificultou o conhecimento e compreensão de como ele lida com elementos da atividade profissional que realiza e quais os efeitos que lhe são causados devido ao tempo que passa trabalhando, às condições que lhe são oferecidas no trabalho, às relações que estabelece com outros profissionais com quem divide suas atividades.

A busca de conforto material em conjunto com a busca incessante de lucratividade por parte das organizações fez surgir a "Sociedade 24 horas", na qual o trabalho é realizado em turnos alternados durante as 24 horas do dia, havendo a necessidade dos trabalhadores permanecerem acordados e alertas em áreas como a de Segurança (Silva, Chaffin, Silva Neto \& Siqueira Júnior, 2010).

O campo de trabalho de garantia de segurança às pessoas ou patrimônios demonstra ser de alto nível de responsabilidade, fazendo com que o trabalhador deposite cargas de energia física e mental para atender às responsabilidades que lhe foram atribuídas. Neste sentido, Silva, Teles, Araújo, Brito e Silva (2013) concluem que os impactos na vida pessoal e profissional do trabalhador da área de segurança são preocupantes, desencadeiam outras questões como o estresse e a fadiga, e que o trabalho em turnos torna-se desgastante por apresentar intensidade no serviço, agravando a saúde e causando diversos impactos, desde problemas físicos até sociais.

Diante da relevância do tema e da escassez de informações em nível local, este estudo empírico e qualitativo teve como objetivo conhecer os efeitos do trabalho no- turno na saúde dos trabalhadores da área de segurança pública e privada de uma cidade do Piauí. Ainda, verificou-se os principais impactos do trabalho e realizou um levantamento dos motivos para a escolha da profissão.

\section{Material e método}

Participaram vinte profissionais que trabalham nas áreas de Segurança Pública e Privada, selecionados de acordo com a sua disponibilidade de serem entrevistados, com idades entre 22 e 59 anos. Todos são do gênero masculino, com tempo de trabalho noturno variando entre quatro meses a 31 anos, contabilizando entre 28 e 56 horas de sono por semana.

Como instrumentos, responderam questionário sociodemográfico e roteiro de entrevista semiestruturada com perguntas elaboradas pelos pesquisadores e relacionadas ao tema pesquisado, abordando o trabalho noturno e seus efeitos na saúde do profissional da área de segurança, a escolha profissional, a conciliação do horário de trabalho com as relações sociais, mudanças na vida e na saúde após a inserção no mercado de trabalho, atividades fora do trabalho, acidentes de trabalho, aspectos positivos e negativos em trabalhar no horário noturno e expectativas em relação à carreira na área.

Quanto aos procedimentos, as entrevistas foram realizadas dentro dos locais de trabalho dos participantes. Independentemente da situação, durante a abordagem foi perguntado a cada um deles se poderia participar da pesquisa e, quando de acordo, teve acesso ao Termo de Consentimento Livre e Esclarecido, contendo informações detalhadas sobre a pesquisa.

Foram seguidas as normas e procedimentos éticos conforme a Resolução no 466/2012 do Conselho Nacional de Saúde, que estabelece as diretrizes e normas regulamentadoras de pesquisas envolvendo seres humanos. A pesquisa foi aprovada pelo Comitê de Ética em Pesquisa da Universidade Federal do Piauí, com o número CAAE 56409716.1.0000.5214.

Para a análise dos dados foi utilizado o programa IRAMUTEQ que realiza diferentes tipos de análises de textos e questionários (Marchand \& Ratinaud, 2012), contribuindo para estudos nos campos das ciências sociais e humanas, possuindo rigor estatístico no uso de recursos técnicos de análise lexical (Camargo \& Justo, 2013).

Para ser incluído no corpus de dados, o respondente deveria trabalhar no ramo da segurança e no horário noturno. Todos os entrevistados, policiais militares, policiais federais, bombeiros militares e agentes de segurança patrimonial, contribuíram com a pesquisa respondendo 
o questionário sociodemográfico e a entrevista semiestruturada.

\section{Resultados}

A Classificação Hierárquica Descendente (CHD) levantou os segmentos de texto e os classificou em função da frequência, foram transformados em 250 segmentos de texto, com 4584 ocorrências, 1119 formas e 659 hapax, que são palavras que aparecem apenas uma vez no texto.

O programa considerou $77,37 \%$ dos segmentos de texto para a análise, satisfazendo o critério mínimo apontado pela literatura de $75 \%$ de aproveitamento do corpus (Camargo \& Justo, 2013). Realizou-se divisões sequenciais no corpus até se originarem quatro classes. A primeira divisão deu origem a dois subcorpus. $\mathrm{O}$ primeiro subcorpus divide-se gerando as Classes 3 e 4, enquanto o segundo subcorpus divide-se gerando as Classes $1 \mathrm{e}$ 2. A divisão do corpus em quatro classes elaborada pelo software pode ser observada na Figura 1.

Cada uma das classes resultantes da CHD é composta pelas palavras mais significativas (maior frequência dentro da classe) e pelas respectivas associações com a classe (chi-quadrado). Dessa forma, a Figura 2, elaborada
FIGURA 1 - Divisão do corpus em classes

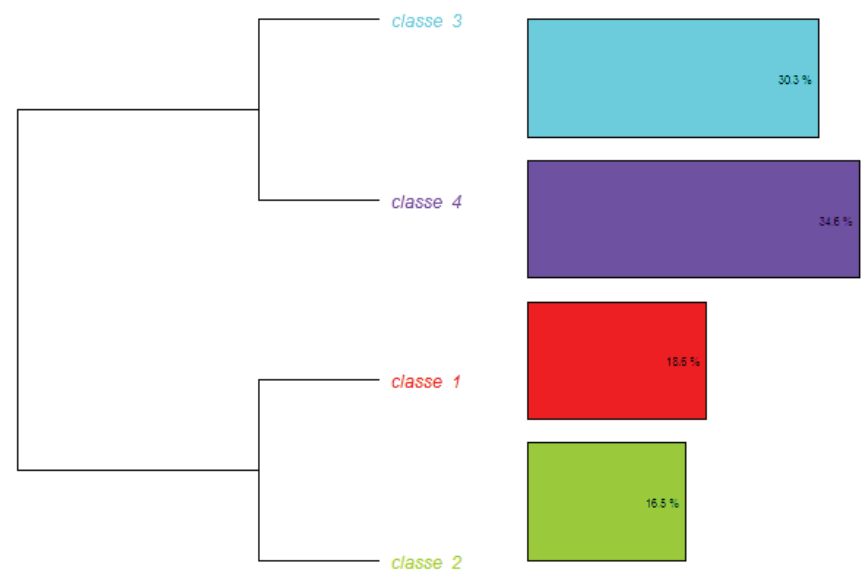

pelos autores, apresenta as 15 palavras que melhor caracterizam cada uma das classes, de acordo com a Figura 1.

A respeito dos conteúdos lexicais das análises textuais, a classe 1 representou 18,62\% dos segmentos de texto, denominada "Fatores motivadores para o trabalho noturno".

FIGURA 2 - Dendograma de classes com palavras mais significativos para o Corpus Segurança.

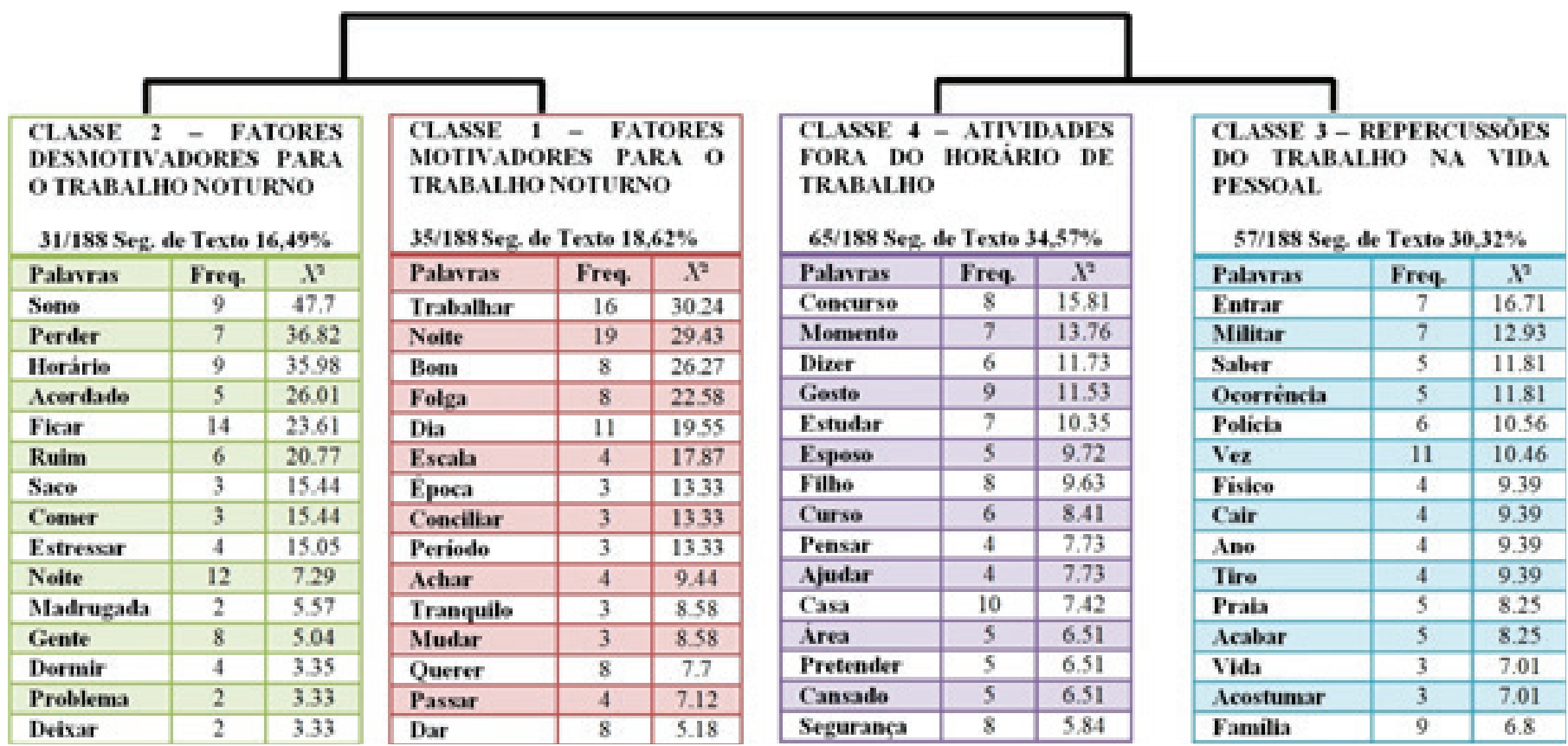


QUADRO 1. Segmentos de texto mais representativos da Classe1.

\begin{tabular}{ll}
\hline $\mathbf{X}^{\mathbf{2}}$ & Segmento de Texto \\
\hline 30.24 & $\begin{array}{l}\text { foi uma questão de oportunidade e de necessidade todo mundo trabalha à noite todo mundo passa pela } \\
\text { escala de } 24 \text { horas de trabalho e } 72 \text { horas de folga }\end{array}$ \\
\hline 29.43 & o fato de trabalhar de dia e de noite também tenho folga de dia e à noite dá para levar bem \\
\hline 26.27 & de noite é bom porque o caboco de dia tem folga aí pode resolver alguma coisa \\
\hline 22.58 & $\begin{array}{l}\text { não quero área de saúde porque o atendimento é em plantão e nessa área não é bom trabalhar à noite } \\
\text { mas como bombeiro eu não tenho objeção em relação a isso }\end{array}$ \\
\hline 19.55 & a empresa quer fazer um acordo para a gente trabalhar 6 meses durante o dia e 6 meses durante a noite \\
\hline
\end{tabular}

Nota: Neste quadro estão contidos apenas os 5 segmentos de texto com os maiores valores de $\mathrm{X}$

A Classe 2, "Fatores desmotivadores para o trabalho noturno", representa 16,49\% dos segmentos de texto e as palavras que melhor se relacionam a esta classe fazem menção ao perder sono devido ao horário de trabalho e as suas consequências.

QUADRO 2. Segmentos de texto mais representativos da Classe2.

\begin{tabular}{ll}
\hline $\mathbf{X}^{2}$ & Segmento de Texto \\
\hline 47.87 & $\begin{array}{l}\text { por causa da farda a gente fica muito suado o ruim é ficar cansado a gente perde muito sono a gente } \\
\text { fica muito cansado }\end{array}$ \\
\hline 36.82 & perco sono não durmo quando estou de plantão mas dá para recuperar fico um pouco estressado \\
\hline 35.98 & perder o sono é ruim aí de madrugada me dá sono aí eu tomo café para espertar \\
\hline 26.01 & $\begin{array}{l}\text { o cansaço prejudica a saúde perder sono não é bom eu não consigo dormir de manhã e nem à tarde só à } \\
\text { noite }\end{array}$ \\
\hline 23.61 & $\begin{array}{l}\text { ninguém fica acordado a noite inteira, cara eu perdi minhas amizades depois que casei agora dou atenção } \\
\text { só para a minha família }\end{array}$ \\
\hline
\end{tabular}

Nota: Neste quadro estão contidos apenas os 5 segmentos de texto com os maiores valores de $\mathrm{X}^{2}$

A Classe 3, "Repercussões do trabalho na vida pessoal", representa 30,32\% dos segmentos de texto, o segundo maior percentual, e seu conteúdo indica a entrada da vida profissional na vida pessoal havendo choque e repercutindo nas relações com família e amigos.

Quadro 3. Segmentos de texto mais representativos da Classe3.

\begin{tabular}{ll}
\hline $\mathbf{X}^{2}$ & Segmento de Texto \\
\hline 15.81 & $\begin{array}{l}\text { fechou meus } 30 \text { anos eu vou para casa quero mais não a vida militar entra na família você tenta viver } \\
\text { uma vida paralela mas acaba entrando em choque }\end{array}$ \\
\hline 13.76 & $\begin{array}{l}\text { nunca me acostumei o pior é quando tem ocorrência e fica a noite toda nela entro } 2 \text { horas e saio } 4 \\
\text { horas }\end{array}$ \\
\hline 11.73 & a vida militar acaba com a gente tenho artrose má circulação nas pernas o cara sai sugado \\
\hline 11.53 & $\begin{array}{l}\text { amo minha profissão não estou aqui pelo dinheiro não quando eu entrei aqui a polícia só me pegava } 1 \\
\text { salário }\end{array}$ \\
\hline 10.35 & a gente se conhecia só da vida militar fora dela, nada, hoje tem mais aproximação \\
\hline
\end{tabular}

Nota: Neste quadro estão contidos apenas os 5 segmentos de texto com os maiores valores de $\mathrm{X}^{2}$

A Classe 4, "Atividades fora do horário de trabalho", representa 34,57\% dos segmentos de texto, o maior percentual, havendo nesta classe menção a estudar para concurso, ajudar em casa em atividades domésticas, não estar realizando no momento atividades físicas que gostaria de fazer. 
QUADRO 4. Segmentos de texto mais representativos da Classe 4.

\begin{tabular}{ll}
\hline $\mathbf{X}^{2}$ & Segmento de Texto \\
\hline 15.81 & é sazonal estudar quando tem concurso eu gosto, mas agora é difí- \\
& cil quando você tem que acordar cedo e dormir mais tarde é ruim \\
\hline 13.76 & ajudo em casa também, no momento não estou fazendo nenhum curso, \\
& tem sim que gostaria de realizar e não estou realizando \\
\hline 11.73 & quando estou em casa ajudo na arrumação da casa minha esposa des- \\
& pediu a funcionária porque diz que só nós 2 damos conta \\
\hline 11.53 & também tenho lazer a questão de estudar eu gosto mas não estou \\
\hline 10.35 & nesse momento \\
\hline & pretendo ser segurança do meu filho quando ele se formar porque \\
& hoje a coisa está séria ajudar a família aí vou largar a farda
\end{tabular}

Nota: Neste quadro estão contidos apenas os 5 segmentos de texto com os maiores valores de $\mathrm{X}^{2}$

\section{Discussão}

Pesquisar o trabalho noturno e seus efeitos na saúde do trabalhador da área de segurança, a compreendendo envolvida em elementos sociais, tecnológicos, econômicos e organizacionais e aqueles que permeiam os processos de trabalho (Benites, Camargo, Goulart Júnior \& Camargo, 2013), ainda, os psicológicos, possibilita entendimento abrangente dos fatores influenciadores da saúde do profissional em razão do trabalho.

$\mathrm{Na}$ Classe 1 constam palavras que fazem menção a trabalhar à noite ser bom devido à folga durante o dia. Existem menções à escala do trabalho em plantão, a conciliar os períodos dentro e fora do trabalho e achar o período noturno como tranquilo para trabalhar.

Nesse contexto de motivações para o trabalho, salienta-se o entendimento de Spector (2012) que as explica como estado interno indutor de uma pessoa a se envolver em determinados comportamentos, envolvendo o direcionamento, a escolha de comportamentos específicos a partir de um grande número de comportamentos possíveis, à intensidade do empenho de uma pessoa ao realizar uma tarefa e à persistência no envolvimento continuado em um comportamento ao longo do tempo.

Os participantes encontraram motivação para se envolverem no trabalho à noite em elementos subjetivos, persistindo neste trabalho ao conceber o período noturno como mais tranquilo para trabalhar por haver menos pessoas nas ruas, ou conseguir folga durante o dia, este período entendido como possível de se resolver problemas burocráticos, por exemplo.

Além disto, outros participantes mencionaram o ganho salarial maior devido aos adicionais noturnos e de periculosidade e/ou insalubridade, a sensação de dever prestar os serviços de segurança para a comunidade e de cumpri-lo, enfatizando a importância da sociedade na colaboração com o trabalho e a característica pessoal de gostar do horário da noite, de sentir-se mais ativo para trabalhar conseguindo melhor rendimento como elementos motivadores para o trabalho. Nesta dimensão, Spector (2012) comenta que o senso de realização proveniente da conclusão bem-sucedida de um importante projeto tem probabilidade de resultar em sentimentos positivos, como orgulho e alegria, conectando-se ao resultado levantado.

A Classe 2, caracterizada como "fatores desmotivadores para o trabalho noturno" faz menção a ser necessário ficar acordado, o que é entendido como algo ruim para alguns dos respondentes. Há menção, também, a "não fico de saco cheio, eu furo o saco", quando o respondente trata dos problemas em seu trabalho como enfrentados, não tolerados.

Tomando a concepção de motivação de Spector (2012) citada anteriormente, os fatores desmotivadores seriam, então, aqueles que imobilizam a trajetória do profissional em suas atividades laborais, empecilhos que dificultam o alcance, ou mesmo o estabelecimento de metas.

Nessa classe foram encontrados efeitos negativos, na saúde do profissional em diferentes formas, constituindo-se em elementos desmotivadores, como expresso em: à noite o estresse é maior, é mais fácil pela manhã. Visibilidade, a criminalidade prefere agir mais à noite, é mais complicado", "na realidade aumentei alguns quilos", e "a alteração do relógio biológico". Ressalta-se que apesar de ser uma classe específica, esses fatores desmotivadores emergiram na fala dos entrevistados nas demais, visto que para eles o trabalho influencia a vida fora do serviço, nas relações estabelecidas nas folgas, "acho que a pessoa que trabalha à noite tem mais tendência de adquirir doença", "primeiro pela questão do sono, problemas no estômago que eu tinha 
antes que piorou porque tomo muito café e Coca-Cola e salgados, é o que a gente encontra à noite pra comer. Agora tenho problemas de concentração, porque o trabalho te deixa alerta e pela perda de sono não consigo mais me concentrar facilmente, então qualquer barulho distrai".

Policial militar entrevistado comentou, ao tratar dos fatores desmotivadores de sua profissão, que "a vida militar acaba com a gente, tenho artrose, má circulação nas pernas, "o cara sai sugado". O militar morre psicologicamente e emocionalmente, é uma morte antecipada, não é só de tiro. Quando a gente está fora do serviço continua alerta. Qualquer coisa a gente está em alerta". Ele percebeu o envolvimento do sofrimento acarretado pela sua atividade laboral militar em aspectos biológicos e emocionais, o morrer psicologicamente e emocionalmente e a permanência no trabalho demonstram o contraste entre a carga de motivação e desmotivação que o trabalho impõe ao trabalhador. A sua formação militar e o seu juramento o envolve em todos os aspectos da vida, ou seja, o militar o é dentro e fora da corporação, com ou sem a farda.

O salário, a falta de estrutura e de equipamentos também surgiram no discurso de profissionais da segurança pública como fatores desmotivadores e que geram adoecimento. Sobre o adoecimento do policial militar, Paulino e Lourinho (2014) corroboram o argumento dos entrevistados quando afirmam que não apenas as condições como a organização do trabalho são determinantes no processo saúde/doença do profissional da segurança pública, pois existem fatores secundários, investimento ineficaz ou mesmo a total falta dele, que podem aumentar a velocidade do processo de adoecimento desses trabalhadores. Ainda, explicam que tanto o cansaço físico, quanto a falta de equilíbrio emocional podem levar esse profissional a se comportar de forma irracional no decorrer das crises e das situações caóticas, com a morte pairando constantemente em sua vida.

Dessa forma, o trabalho militar é concebido como em constante estado de vigilância, a exigência de responsabilidade sobre si e sobre os companheiros nas ocorrências, com atenção aos procedimentos, aos envolvidos nas situações em que atuam, vítimas e infratores e população curiosa que se aglomera nos casos que atendem. Sobrecarga de funções que pode culminar no surgimento ou acentuação de sintomas e de predisposições ao adoecimento físico e psicológico, sobretudo quando atuam em horário em que o corpo requer descanso.

A Classe 3 agrupou palavras em torno das repercussões do trabalho noturno na vida pessoal dos trabalhadores, envolvendo efeitos na saúde e os impactos na vida do profissional, com referências ao esgotamento que o trabalho acarreta e a entrada da vida profissional na vida pessoal, bem como ao choque que pode acontecer nesse encontro.

Alguns participantes reclamaram sobre o trabalho influenciar nas relações pessoais - "atrapalha muito é com meus irmãos, quase não vejo eles. Antes eu ia para a igreja, agora não vou mais, eu fico cansado", "com a minha esposa é um pouco complicado. Eu passo o dia com minha filha, mas na noite que estou trabalhando eu não vejo ela", ou sobre o trabalho surgir entre os assuntos conversados nos momentos fora dele, momentos de lazer - "você não pode levar o trabalho para dentro de casa, eu procuro ocupar essa ausência dentro de casa. Mas quando a roda de amigos é da polícia, o assunto é polícia, é ocorrência", e, contrariamente, outros participantes afirmaram que conseguem administrar o tempo de forma satisfatória entre as obrigações do trabalho e os momentos com família e amigos, aproveitando para o lazer, com passeios, viagens, conforme fala um dos entrevistados - "uma das coisas boas do meu serviço é que dá para conciliar família, amigos".

Stepansky e França (2008) lançam luz ao tema equilíbrio entre trabalho e vida pessoal ao proporem que é papel da organização buscar estratégias para que o trabalho seja realizado de forma mais agradável, reduzindo o estresse e flexibilizando o tempo do trabalhador. Trata-se de possibilidade para a transformação das relações com o trabalho e dentro dele, promovendo alternativas para que seja realizado em condições suportáveis e com qualidade de vida, favorecendo a participação do trabalhador em atividades que viabilizem seu bem-estar e saúde.

Como importante componente da vida, o trabalho proporciona recursos que ultrapassam aqueles para o sustento, como salário e benefícios trabalhistas - ele supre necessidades da vida, senso de propósito e contato social, sendo inevitável que as pessoas reajam emocionalmente aos eventos e situações de trabalho (Spector, 2012), logo deve ser repensado e pautado no conhecimento sobre o trabalhador, reconhecimento de deficiências e potencialidades e da importância das suas relações e afetos não restritos à produtividade.

A Classe 4 foi denominada como atividades fora do horário do trabalho, a classe com a maior significância, contendo palavras que se relacionam a estudar para concurso, ajudar em casa em atividades domésticas, não ter no momento atividades físicas que gostariam de fazer.

Algumas das falas a respeito das atividades extras ao trabalho demonstram que os momentos de folga são organizados em função de atividades esportivas e contato com familiares e amigos - "só faço atividade física, encontro os amigos de forma esporádica", "a minha folga eu tiro para família, por isso não faço serviço extra, pra ter tempo pra 
essas pessoas, pra família, amigos, é a função da folga", "futebol, academia, na hora que eu chego eu levo logo minha filha para a escola, aí durmo e acordo para buscar ela", "quando eu estou de folga vou à casa da minha namorada", "no fim de semana saio, vou à piscina e à praia", "saio para caminhar, espairecer mesmo, também gosto de fazer visita aos familiares e irmãos da igreja".

As atividades fora do trabalho na segurança foram demonstradas pelos participantes como oportunidades de lazer, de estabelecimento de relações sociais e de práticas de exercícios. Silva, Souza, Rossi Filho, Silva e Rigoni (2017) informam que as atividades físicas ao serem consideradas do ponto de vista do lazer, devem ter para os sujeitos um sentido de satisfação pela própria atividade, além de lhes proporcionarem a construção de valores em prol de uma vida melhor. Ou seja, não devem confundir a prática de atividades físicas no tempo disponível como forma de minimizar ou evitar doenças.

Além desse aspecto, houve participante que compreendeu o exercício e o condicionamento físico como uma atividade que gostaria de realizar, para o relaxamento das tensões do trabalho, do estresse e cansaço - "rúgbi é meu esporte, ando de moto para relaxar porque ando muito estressado, eu faço o almoço lá em casa, fazer trilhas".

Sobre o estresse relatado pelo participante, Silva (2019) explica que se trata de um termo ao qual que tem sido conferido pluralidade de significados. Goulart Junior e Lipp (2008), considerando o ser humano numa visão biopsicossocial, entendem que ele está submetido a mudanças rápidas e significativas em diferentes setores de sua vida e precisa desenvolver capacidade adaptativa, mobilizando energia física, mental e social para que se adapte a elas. No entanto, pode acontecer demasiada incongruência entre a sua capacidade de adaptação em relação à velocidade das transformações, resultando em situações de conflito e desequilíbrio, se instaurando as situações de estresse.

Diante dos resultados, conclui-se que o trabalho noturno repercute na saúde dos profissionais da área de Segurança pública e privada de uma cidade do Piauí.. As queixas sobre efeitos como o cansaço físico, o cansaço psíquico, o estresse, a desregulação do ciclo do sono e os impactos gerados nos relacionamentos sociais, representados pela dificuldade em encontrar familiares, amigos, grupos de convivência como a igreja, falta de energia para aproveitar as folgas em momentos de lazer, possuem relação com o desempenho laboral. Este está relacionado com as queixas, sendo consequências das relações estabelecidas entre profissional e trabalho.
O trabalho figura, para a maioria dos profissionais entrevistados, como fundamental, algo pelo qual tem paixão e dedicam-se com afinco. Todavia, não é possível considerar tais características como suficientes para os trabalhadores superarem as dificuldades que lhes são impostas pelo trabalho noturno, seria depositar neles absoluta responsabilidade em desvencilharem-se dos fatores que os afetam negativamente. $\mathrm{O}$ trabalho pode ser gerador de sofrimentos e de adoecimentos, mas pode ser um lugar onde se proporciona qualidade no exercício das tarefas devidas, evitando, ou tornando menos frequente os problemas à saúde.

Estudos a respeito do trabalho noturno e as suas consequências para a saúde e outras dimensões vitais com a categoria profissional investigada e demais que laborem naquele turno são recomendadas, de modo a constituírem fontes de informação capazes de implementar ações voltadas à prevenção e promoção de saúde dos profissionais e nas organizações.

\section{Referências}

Araújo, R. R., \& Sachuk, M. I. (2007). Os sentidos do trabalho e suas implicações na formação dos indivíduos inseridos nas organizações contemporâneas Meanings attributed to labor and their implications in contemporary organizations. REGE. Revista de Gestão, 14(1), 53.

Benites, A. C., Camargo, I. S., Júnior, E. G., \& Camargo, M. L. (2013). Relação entre Transtorno do Ciclo Vigília-Sono e Trabalho Noturno: desafios à segurança e saúde do trabalhador. Revista Laborativa, 2(2), 86-107.

Borsoi, I. C. F. (2007). Da relação entre trabalho e saúde à relação entre trabalho e saúde mental. Psicologia \& Sociedade, 19(1), 103-111.

Camargo, B. V., \& Justo, A. M. (2013). IRAMUTEQ: um software gratuito para análise de dados textuais. Temas em psicologia, 21(2), 513-518.

Goulart Junior, E. \& Lipp, M. E. N. (2008). Estresse entre professoras do ensino fundamental de escolas públicas estaduais. Psicologia em Estudo, 847-857.

Marchand, P., \& Ratinaud, P. (2012). L'analyse de similitude appliquée aux corpus textuels: les primaires socialistes pour l'élection présidentielle française (septembre-octobre 2011). Actes des 11eme Journées internationales d'Analyse statistique des Données Textuelles. JADT, p. 687-699.

Paulino, F. R., \& Lourinho, L. A. (2014). O adoecimento psicológico do policial militar do Ceará. Revista Trabalbo e Sociedade, Fortaleza, 2(2), 58-77.

Silva, C. L., Souza, M. F., Rossi Filho, S., Silva, L. F., \& Rigoni, A. C. C. (2017). Atividade física de lazer e saúde: uma revisão sistemática. Mudanças-Psicologia da Saúde, v. 25, n. 1, p. 57-65.

Silva, G. D. N. (2019). (Re) conhecendo o estresse no trabalho: uma visão crítica. Gerais: Revista Interinstitucional de Psicologia, 12(1), 51-61.

Silva, E. C. G., Chaffin, R. A., Silva Neto, V. C. \& Siqueira Júnior, C. L. (2010). Impactos gerados pelo trabalho em turnos. Perspectivas OnLine 2007-2011, 4(13).

Silva, M. F. M., Teles, L. M. S., Araújo, K. F., Brito, T. R. S., \& Silva, J. S. (2013). Trabalho Diurno e Noturno: principais impactos do trabalho em turnos para a saúde de vigilantes. Revista Organizações em contexto, 9(17), 183-204.

Spector, P. (2012). Psicologia nas organizações. 4. ed. São Paulo: Saraiva.

Stepansky, D. V., \& França, L. (2008). Trabalho e vida pessoal: o equilíbrio necessário. Boletim Técnico do SENAC, 34(1*), 64-71.

Submetido em: 30-6-2019

Aceito em: 17-12-2019 